Aletria, Belo Horizonte, v. 28, n. 1, p. 201-218, 2018

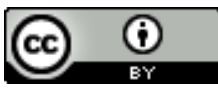

\title{
David Foster Wallace e a vertigem da notação: transformações da descrição na ficção contemporânea
}

\section{David Foster Wallace and the Vertigo of Notation: Transformations of Description in Contemporary Fiction}

\author{
Tauan Fernandes Tinti \\ Universidade Estadual de Campinas, Campinas, São Paulo / Brasil \\ tauantinti@gmail.com
}

Resumo: Este ensaio tem como ponto de partida a observação de uma tensão significativa entre as preocupações constantemente declaradas pelo escritor norteamericano David Foster Wallace em seus romances e ensaios e o seu uso de certos procedimentos narrativos que em última instância remontam aos becos sem saída do discurso indireto livre de matiz flaubertiano, tal como analisado por Moretti. Através do contraste entre as leituras de Moretti e de Rancière sobre as transformações sociais expressadas pela forma narrativa de Flaubert, defendo a hipótese de que Wallace busca transmitir por meio de sua ficção um aprendizado da atenção - na base da respiração narrativa da prosa do século XIX -, que entra em dissonância com as transformações sofridas pela técnica no decurso do processo histórico desde então.

Palavras-chave: David Foster Wallace; The Pale King; efeito de real; ficção contemporânea.

Abstract: This essay starts with the consideration of a significant tension between thematic constantly asserted by the writer David Foster Wallace throughout his fictions and essays and his usage of certain narrative procedures that ultimately lead back to the dead ends of the Flaubertian free indirect discourse, as discussed by Moretti. Through a contrastive reading between Moretti's and Rancière's analyses of the social changes that are given expression through Flaubert's narrative form, this work explores the hypothesis that Wallace seeks to transmit through his fiction a kind of learning of attention - which forms the basis of Realist prose - that ultimately goes against the very transformations undergone by narrative technique in the course of the historical process.

Keywords: David Foster Wallace; The Pale King; reality effect; contemporary fiction. 
1.

James Wood, o crítico britânico que foi por muitos anos um dos principais resenhistas da revista The New Republic, foi acusado por Walter Kirn, em uma resenha de seu estudo introdutório sobre Como funciona a ficção, de ter dado a David Foster Wallace a honra dúbia de ser um de seus "vilões estéticos". ${ }^{1}$ Wood, em uma resposta em parte motivada pelo suicídio do escritor em 2008, ${ }^{2}$ argumentou não ser bem esse o caso, encontrando no problema principal que vê no projeto estético de Wallace também um de seus maiores trunfos: de um lado, o escritor teria sido talvez quem mais levou a sério uma "perigosa tautologia" central à literatura contemporânea dos EUA, ligada à representação de uma linguagem "saturada [...] pelos meios de comunicação de massa" que leva à degradação da própria linguagem da representação, sendo "pavorosamente feia" e chegando a doer quando se estende por mais de uma ou duas páginas; ${ }^{3}$ de outro, esse mesmo compromisso mimético de fundo vanguardista aponta para uma "temeridade estilística" louvável, especialmente à medida que entra em tensão com certo "conservadorismo metafísico" do escritor, cuja superação potencial, trazendo consigo a possibilidade de resultados literários notáveis, ficou não realizada por conta de sua morte.

Já em sua resenha de Oblivion - Stories, Wood havia sido bem menos ambíguo em sua avaliação dos méritos literários do escritor, simplificando o problema na medida que também o tornava manuseável: sua versão de Wallace tem tanto um olho notável para o detalhe expressivo e a imagem comicamente precisa (por exemplo, "a career beverage waitress" [uma auxiliar de garçom nata]), quanto uma capacidade ímpar de absorver no ritmo de sua respiração narrativa os idioletos médios característicos dos habitats de seus personagens - seja a mistura de siglas e marcas de produtos, linguagem burocrática e autoajuda empresarial de Terry Schmidt, funcionário de uma empresa de marketing especializada em focus-testing de "Mr Squishy"; seja a superficialidade pretensamente $\mathrm{cool}$, autoindulgente e um tanto oca que forma a atmosfera da redação de uma revista de moda com pretensões semissérias de relevância cultural, em "The Suffering Channel” - e esse é o seu lado bom. Já o lado ruim -

${ }^{1}$ Cf. KIRN. A Not So Common Reader.

${ }^{2}$ Cf. WOOD. Remembering David Foster Wallace.

${ }^{3}$ WOOD. Como funciona a ficção, p. 39-41. 
que torna o livro "talentoso, frustrante e enfim intolerável"4 - é um pouco mais complexo: ainda que Wood reconheça em Wallace um "interesse profundo por seres humanos", sua forma negativa de manifestação teria um alcance dos mais restritos, já que o cenário, estéril em quase todos os sentidos - à exceção notável da abundância material recorrente nos contos -, não deixa espaço para qualquer possibilidade de interioridade que não se mostre mera miragem.

Da perspectiva de James Wood, então, o mundo de Oblivion - e da ficção de Wallace em geral - é, em uma palavra, estéril demais. A sociedade americana, inteiramente socializada, para tomar emprestada a expressão de Adorno, ${ }^{5}$ conformaria os indivíduos aos seus moldes com tamanha força que qualquer manifestação enfática de uma vida interior não tem como vir à luz - o que, é importante ressaltar, de modo algum implica a ausência de sofrimento subjetivo. Forçando um pouco o ouvido, pode-se perceber na reserva do crítico à literatura wallaceana os ecos distantes (ainda que esvaziados de carga dialética) da Teoria do romance de um Lukács pré-marxismo: a rigidez das estruturas sociais tornadas "segunda natureza" forma "um complexo de sentido petrificado que se tornou estranho, já de todo incapaz de despertar a interioridade; é um ossuário de interioridades putrefatas"; 6 é a esse pesadelo da socialização que Wallace daria forma em contos como os de Oblivion.

Esvaziados de carga dialética, acabou de ser dito - e é algo que merece explicação. Wood julga compreender o que está em questão na ficção de Wallace, por ele encarada, não sem alguma razão, como um prolongamento tardio e ambivalente da poética difusa de autores tão diferentes entre si quanto Thomas Pynchon, Donald Barthelme, William Gaddis, ou John Barth (e um pouco mais adiante, Don DeLillo, David Markson, Nicholson Baker... a lista poderia se estender). Do outro lado desse cercado, que corresponde ao da estética pós-modernista em sentido amplo, ${ }^{7}$ haveria espaço para uma tradição um pouco diferente,

\footnotetext{
${ }^{4}$ WOOD. The Digressionist, p. 29.

${ }^{5} \mathrm{Cf}$. ADORNO. Introdução à sociologia.

${ }^{6}$ LUKÁCS. Teoria do romance, p. 64.

${ }^{7}$ Para um panorama sobre diversas questões envolvidas na discussão sobre o pósmodernismo literário de língua inglesa, conferir, por exemplo, os influentes estudos de Fredric Jameson: Postmodernism, or, The Cultural Logic of Late Capitalism (1991) e As sementes do tempo (1997).
} 
menos preocupada com a experimentação formal e mais voltada para a representação da interioridade - ou melhor, com um "interesse profundo em seres humanos" que não se manifesta apenas negativamente: seria esse o caso, muito grosso modo, de escritores como John Updike, Saul Bellow, Philip Roth, o Paul Auster tardio, etc. A posição de James Wood não é necessariamente representativa - Infinite Jest fez, afinal, um sucesso estrondoso, e entre outras coisas por seu lado "humano" -, mas ainda assim seu modo de armar a oposição tem sua utilidade. Wallace, um dos representantes contemporâneos máximos dos chamados "romancistas de imersão", faz uso de uma técnica relativamente incomum entre seus pares: não são tanto os seus enredos que estão repletos de personagens tipicamente americanos, mas as suas próprias frases é que são inchadas de uma linguagem "degradada pelo uso cotidiano" - e é precisamente esse inchaço que não deixa espaço para o aparecimento de interioridades em sentido forte, que Wood segue acreditando encontrar nos monólogos interiores de outros romancistas. O problema com Wallace, e com a narrativa de imersão como um todo, seria o de que "o único jeito que ela encontra de representar algo é dar-lhe corpo, ao invés de apontar em sua direção". 8

Trata-se de um problema cujo lastro histórico de modo algum se reduz à ficção recente produzida nos Estados Unidos. Em sua defesa contra a já mencionada acusação de Walter Kirn, Wood aponta com lucidez para sua nascente: a ficção de Wallace teria sido discutida, em Como funciona a ficção,

como um exemplo extremo de uma tensão que creio ser endêmica na ficção pós-flaubertiana, que é a questão, como colocou Martin Amis certa vez, de "quem está no comando": é o autor dotado de estilo, que vê o mundo por meio de sua linguagem deslumbrante, ou são os seus personagens, provavelmente dele menos dotados, que estão tomando emprestadas as palavras do autor? ${ }^{9}$

\footnotetext{
${ }^{8}$ WOOD. The Digressionist, p. 29.

9 "as an extreme example of a tension I think is endemic to post-Flaubertian fiction, which is the question, as Martin Amis once put it, of "who's in charge": is it the stylish author, who sees the world in his fabulous language, or his probably less stylish characters, who are borrowing the author's words?" (WOOD. Remembering David Foster Wallace).
} 
Ficção pós-flaubertiana: é esse o marco que interessa - e com ele, sua grande conquista formal: o uso sistemático do discurso indireto livre. Pois o que Wood chama de narrativa de imersão diz respeito, em última instância, à contaminação da voz narrativa pela linguagem do grupo social, cujo meio serve de cenário aos acontecimentos ficcionais: tiques linguísticos comuns, referentes previsíveis a serem incluídos em analogias, organizações sintáticas que expressam certos tipos de mentalidade, com especial importância tanto para a parataxe nas descrições quanto para uma recursividade nos raciocínios que, ao tentar disfarçar a ausência de saída de certos padrões de pensamento, acaba por expô-la ainda mais e como que à revelia da consciência narrativa trata-se do terreno inquestionável do discurso indireto livre. Mas, mais do que isso, o que o argumento de James Wood assume como pressuposto declarado - e, diríamos, questionável - é que é possível representar certas formas de subjetivação, em última instância ligadas a processos sociais, apenas "aponta[ndo] em sua direção" - ou mesmo que as diferentes técnicas narrativas se encontram todas mais ou menos disponíveis em seu conjunto, com graus semelhantes de legitimidade e capacidade de expressão de uma dada situação histórica.

Para dizer o mínimo, pode não ser bem esse o caso. Pois a monotonia narrativa presente em parte considerável da ficção de Wallace não consiste em um subproduto periférico, mera reação adversa produzida por seu estilo. Ao contrário, a hipótese aqui é que ela é inerente a seu projeto ficcional - não como fim em si mesma, mas como meio necessário para expressar alguma outra coisa. Trata-se, em suma, de uma monotonia (ou mesmo chatice) programática, que vai se tornando cada vez mais central na produção ficcional do escritor, e que alcança seu auge em The Pale King: um romance que, mesmo ainda inacabado ${ }^{10}$ somava já mais de 500 páginas próximas de uma versão final, e cujo tema reiteradamente declarado é a própria dificuldade de se lidar com o tédio cotidiano - ou a "soul-crushing boredom" [monotonia de esmagar a alma] de um emprego burocrático como o dos agentes da Receita Federal americana. As técnicas narrativas em muito se desenvolveram e modificaram desde então, mas, a se considerar os problemas peculiares envolvidos na última criação de

${ }^{10}$ Para uma exposição do estado de acabamento do romance quando da morte de Wallace, cf. a introdução do editor Michael Pietsch a The Pale King. 
Wallace, elas não parecem tanto assim ter saído do lugar - o que nos leva a indagar quais seriam os motivos disso.

\section{2.}

O crítico Franco Moretti conclui "O século sério", um poderoso estudo sobre as relações entre a preponderância crescente das descrições (e das catálises barthesianas) nos romances do século XIX, o desenvolvimento do discurso indireto livre e as transformações sociais relacionadas à expansão do capitalismo e ao crescimento da classe média burguesa, com a ideia de que o "estilo sério", resultante de tais relações, "[c] ercado por todos os lados, e provavelmente cansado de si, [...] rendeu-se e saiu de cena". ${ }^{11}$ Ainda que a técnica tenha sido levada ao beco sem saída em que, por fim, veio a se encontrar por uma série de fatores que escapam ao nosso escopo aqui, ao menos um deles surge como crucial: com o indireto livre plenamente desenvolvido, tal como se pode ver nos romances de Flaubert, tanto a voz do narrador quanto a dos personagens, a quem ele supostamente empresta a linguagem, são substituídas por uma terceira entre ambas, "a voz ligeiramente abstrata e cabalmente socializada do contrato social efetivado". ${ }^{12}$ Uma voz média, nem coletiva, nem individualizada, degenerada por Flaubert até ser excetuando-se as descrições, que merecem também discussão à parte - um amontoado de lugares comuns contra os quais não há mais nada que faça frente; qualquer forma de oposição à doxa se torna, segundo Moretti, simplesmente inimaginável. Em Oblivion e especialmente em The Pale King, a situação é praticamente a mesma: aproveitando a expressão de James Wood, poderíamos dizer que são narrativas de imersão por falta de escolha, já que nelas não existe lado de fora - nem no mergulho para dentro da interioridade dos personagens (que só reproduzem os lugares comuns que a formam), nem em uma perspectiva privilegiada a partir da qual seja possível julgar a ação ou o próprio meio social sem ser por ele ao menos parcialmente determinada; em outras palavras, não parece haver qualquer possibilidade de um horizonte normativo que

\footnotetext{
${ }^{11}$ MORETTI. O século sério, p. 32. O ensaio foi depois parcialmente reformulado como um dos capítulos de $O$ burguês, sua mais recente produção de fôlego; os dois textos são usados aqui de forma relativamente intercambiável.

${ }^{12}$ MORETTI. O burguês, p. 102.
} 
não redunde na reiteração do existente. Trata-se de um ressurgimento no mínimo curioso, na ficção de Wallace (e talvez não só nela), do ponto de culminância do estilo sério, quase 130 anos depois: na expressão feliz (!) de Moretti, "é o terror de Bouvard e Pécuchet: não há bem como distinguir um romance sobre a estupidez de um romance estúpido"; ${ }^{13}$ mutatis mutandis, não há como distinguir um romance sobre a monotonia de um romance monótono.

Para um efeito como esse, não se poderia, como quer Wood, simplesmente apontar em direção ao problema. E não é à toa que, por mais doloroso que possa ser atravessá-lo, o "estilo sério" de Wallace frequentemente se estenda por bem mais do que uma ou duas páginas; ${ }^{14}$ uma boa justificativa para tanto vem da pena de Flaubert, que já se antecipara à crítica de Wood, mas bem poderia ter saído da caneta esferográfica de Wallace. Em uma carta a Ivan Turguêniev de julho de 1874, Flaubert se defende da ressalva feita pelo amigo russo de que as entediantes aventuras de Bouvard e Pécuchet pelos diferentes campos do saber precisariam primar pela brevidade. O tema,

Se for tratado com brevidade, de uma forma concisa e leve, será uma fantasia mais ou menos espiritual, mas sem alcance e sem verossimilhança, enquanto que, se for detalhado e desenvolvido, parecerei acreditar em minha história - e será possível torná-la algo sério e até assustador. O grande perigo é a monotonia e o tédio. É exatamente o que, todavia, me assusta. ${ }^{15}$

O mero volume de texto - ou, se quisermos, de informação narrativa - como capaz de operar uma transformação qualitativa no horizonte de expectativa dos leitores e em suas reações - ninguém, afinal, seria tão louco de escrever centenas de páginas tão enfadonhas sem algum bom motivo. No caso de Flaubert, ele pareceria levar sua série de absurdos medíocres a sério, e com isso teria uma espécie de carta branca que permitiria "exalar ressentimento", "vomitar raiva",

\footnotetext{
${ }^{13}$ MORETTI. O século sério, p. 32.

${ }^{14}$ Os exemplos são inúmeros. Fiquemos apenas com um: o infame capítulo 25 de The Pale King, que chega a ser dividido em colunas, se estende por quatro páginas de descrição de gestos mecânicos e repetitivos dos funcionários em uma sala da Receita Federal, e consiste em não mais do que isso, à exceção de duas estranhas frases.

${ }^{15}$ FLAUBERT. Bouvard e Pécuchet, p. 17, grifo meu.
} 
"ejacular cólera", "purificar indignação"16 - em suma, dar vazão a todo o seu conhecido desprezo pela burguesia francesa de que era membro. Wallace, contudo, tem planos bastante distintos desses; ainda que seja possível detectar marcas de desdém em sua narração, ${ }^{17}$ em The Pale King é diversas vezes declarada a intenção de se ensinar algo diferente da superioridade enojada de um Flaubert:

A chave burocrática subjacente é a capacidade de lidar com a monotonia. Funcionar direito em um ambiente que exclui tudo de vital e humano. Respirar, por assim dizer, sem ar.

[...]

É a chave para a vida moderna. Se você for imune à monotonia, não existe literalmente nada que você não possa realizar. ${ }^{18}$

E um projeto como esse entra em tensão constante não só com a filigrana descritiva, mas especialmente com a própria mecânica básica do discurso indireto livre: conforme aponta Moretti, uma técnica narrativa como a de Madame Bovary "é o término lógico daquele longo processo que desobrigou a literatura europeia de suas funções didáticas, substituindo o narrador onisciente". ${ }^{19}$ Um livro entediante sobre o tédio, mas por meio do qual seus leitores podem aprender uma forma de saber que é especialmente relevante para lidar com aquele que é, segundo o narrador, um dos principais desafios do presente: a coisa toda soa como um retorno a formas anteriores de narração, relacionadas à transmissão de uma experiência que, sabe-se no mínimo desde o célebre ensaio de Benjamin a partir de Leskov, ${ }^{20}$ é incompatível com o desenvolvimento do romance - por ser também incompatível com transformações sociais

\footnotetext{
${ }^{16}$ São todas expressões do próprio escritor, tal como constam nas cartas citadas na introdução à tradução brasileira de Bouvard e Pécuchet.

${ }^{17} \mathrm{O}$ uso exageradamente constante da terminologia terapêutica é reconhecido por Zadie Smith como fonte de "risadas baratas, provocadas de um jeito barato demais" (SMITH. Brief Interviews with Hideous Men: The Difficult Gifts of David Foster Wallace, p. 274). 18 "The underlying bureaucratic key is the ability to deal with boredom. To function effectively in an environment that precludes everything vital and human. To breathe, so to speak, without air. [...] It is the key to modern life. If you are immune to boredom, there is literally nothing you can't accomplish" (WALLACE. The Pale King, p. 440, tradução minha).

${ }^{19}$ MORETTI. O burguês, p. 103-104.

${ }^{20}$ Cf. BENJAMIN. O narrador: considerações sobre a obra de Nikolai Leskov.
} 
de mais amplo alcance. Não se pode ter tudo, quase poderia ser dito a Wallace - mas é mesmo assim? A questão pode ser vista também de outro ângulo, que pode no mínimo ajudar a entendê-la melhor.

Passemos então a uma segunda versão do realismo de Flaubert como forma de ligá-lo ao presente - a de Jacques Rancière. Explorada ao longo de diversos livros e ensaios, a questão que Rancière vê no cerne da estética flaubertiana é sintetizada em seu livro mais recente: $O$ fio perdido. Começando por sua polêmica conclusão, que liga Flaubert a Joseph Conrad e por fim a Virginia Woolf, os três eleitos como momentos representativos de uma dinâmica que em muito os ultrapassa: "Os romancistas absorveram o poder dos anônimos na respiração impessoal da frase antes de entregá-lo à tirania da intriga. A justiça poética da ficção se baseia nessa injustiça primeira."21

$\mathrm{O}$ argumento geral é conhecido: a despeito de quaisquer intenções políticas por parte de um escritor reconhecidamente conservador como Gustave Flaubert, um realismo como o de Madame Bovary - ou, melhor ainda, o do conto "Um coração simples" - é fundamentalmente democrático naquilo que realiza: a igualdade radical de todas as coisas e sensações, tanto do ponto de vista formal quanto do de seus conteúdos. Ainda que não tenhamos espaço aqui para explorar as complicações do argumento de Rancière, fiquemos ao menos com o seguinte: enquanto Moretti argumenta em "O século sério" que os momentos em que nada de importante acontece do ponto de vista da trama passam a ganhar uma importância cada vez maior nos romances do século XIX, e mesmo a se sobrepor aos momentos de decisão (ou bifurcação, ou função cardinal) narrativa, que consequentemente acabam por ceder cada vez mais terreno, Rancière vê nesse mesmo movimento a dissolução da oposição formal entre detalhe irrelevante e acontecimento significativo, que por sua vez se desdobra no esfacelamento tendencial do princípio de causalidade narrativa, a ser efetivamente cumprido na arte do século XX. Mas o argumento do filósofo vai além: erradicada a diferença entre acontecimento significativo e insignificante, desaparece junto com ela a separação entre aqueles que agem - os de cima, até então tidos como sujeitos da história - e os que são apenas comandados, e que sofrem as consequências das ações de seus superiores. Não é tanto que a partir de então todos possam igualmente agir, mas sim que a própria concepção

${ }^{21}$ RANCIÈRE. O fio perdido, p. 74. 
de o que seria uma ação se transforma por meio da dissolução das relações de causa e consequência, já que seus efeitos deixam de poder ser medidos adequadamente de acordo com um modelo que enfim surge como limitado, ou mesmo ultrapassado - e que serviu de base, ainda segundo Rancière, à ciência da história. Transfigurada a ideia de ação, ela se combina com a passividade da qual até então se separava, e é na verdade essa mistura que passa a poder vir de qualquer lugar, ser provocada por qualquer coisa, e em qualquer pessoa: no novo regime que se anuncia - ou, no vocabulário de Rancière, no novo modo de partilha do sensível - não há mais lugar para uma diferença hierárquica entre as sensações dos senhores e as dos servos - digamos, entre a intensidade dos sofrimentos de um jovem príncipe Hamlet, dilacerado por uma indecisão paralisante, e a paixão intensa de uma empregada doméstica por um papagaio recebido de presente de sua patroa, como é o caso da Felicité de "Um coração simples".

A citação de Rancière se refere aos desdobramentos dessa nova lógica, tal como surge na narrativa realista. Pois o fluxo indiferenciado de fenômenos e as sensações a eles correspondentes não são a única coisa em jogo nos romances da época: ao contrário, há ainda intriga na narrativa do século XIX, que não deixa de servir de mecanismo de sustentação para aquilo que realmente passa a cada vez mais importar. Em um valioso ensaio dedicado à relação de Deleuze com a literatura, Rancière define a tensão entre essas duas dinâmicas distintas como sendo aquela entre, de um lado, as sequências narrativas adequadas ao sistema molar representativo e, de outro, a força molecular dos detalhes representativos, que de fato correspondem à nova possibilidade de organização do sensível. ${ }^{22}$ Em termos claros - e é essa a chave da questão que estamos aqui esboçando -, o narrador extrai de novas configurações da experiência sensível - isto é, a possibilidade de qualquer coisa suscitar qualquer sensação em qualquer pessoa - o tutano, que passa a fazer parte da "respiração impessoal da frase", e devolve aos supostos sujeitos dessa nova configuração justamente a forma anterior de organização causal, deles diferenciando-se e com isso submetendo-os à já referida "tirania da intriga". Longe de corresponder a uma condenação inconteste da ficção flaubertiana, o argumento de Rancière assinala uma dialética inerente à relação entre partilha do sensível e forma narrativa, com

${ }^{22}$ RANCIÈRE. Deleuze, Bartleby and the Literary Formula, p. 151-153. 
uma narrativa híbrida que se alimenta da força à qual ela mesma ajuda a garantir visibilidade, mas que no mesmo movimento neutraliza seu potencial transformador: Emma, a filha de um fazendeiro que depois se casa com o médico da vila Charles Bovary - pessoas absolutamente comuns, sem qualquer ascendência especial -, precisa morrer ao final do romance, pois não entendeu aquilo que sua própria história serve para expressar. Nas palavras de Rancière, Flaubert "sacrifica o personagem de cujo poder igualitário subversivo ele se apropriou para transformá-lo no poder impessoal da escrita". ${ }^{23}$

Depois de 151 anos - Madame Bovary é de 1857, The Pale King deixou de ser escrito em 2008 -, Wallace parece disposto a finalmente reparar a injustiça cometida. Pois a lição que ele busca transmitir aos leitores - a importância e a capacidade de se prestar atenção em qualquer coisa, por mais entediante que ela possa parecer a princípio - é precisamente, nos termos de Rancière, a lição do ficcionista, roubada daqueles que, como Emma, vivem a vida comum e anônima. O problema é que a lição pode já ter ficado caduca, já que a forma que ela servira para alimentar sofreu ela mesma os efeitos do processo histórico: para além da zona de ação do discurso indireto livre, a técnica descritiva na ficção de David Foster Wallace teve sua dinâmica de outrora profundamente abalada e distorcida, possivelmente tendo deixado de funcionar nos moldes do realismo flaubertiano.

3.

Passemos rapidamente à conversão de Cris Fogle, com a revelação de sua vocação para ser uma espécie de pastor de dados no IRS (Internal Revenue System), a Receita Federal americana, tal como inventada por Wallace em The Pale King. Trata-se do clímax de uma longa entrevista em que o funcionário (fictício) conta suas memórias, formando de longe o maior capítulo do romance. Fogle chegara à idade adulta, no final dos anos 1970, sem perspectivas de vida muito diferentes da de usar drogas recreativas nas redondezas de alguma televisão. A morte do pai impulsiona o rapaz a uma mudança de atitude e, enquanto tenta concluir uma graduação até então empurrada com a barriga, acaba indo parar por engano em uma aula de contabilidade avançada. O professor substituto

${ }^{23}$ RANCIÈRE. O fio perdido, p. 36. 
faz um breve discurso de encerramento do curso, que Fogle experimenta como uma pequena epifania, ruminada ao longo de uma boa dezena de páginas. Mas antes de discutirmos o seu núcleo: David Wallace (isso mesmo), o narrador do romance - debochadamente definido como "uma espécie livro de memórias vocacional" ${ }^{24}$-, menciona que a tendência a se perder em detalhes supérfluos garantiu ao rapaz o apelido de "irrelevante Cris Fogle". Sua epifania com o professor substituto de fato o levou até um emprego no IRS, mas ele parece ter aprendido apenas parcialmente a lição que "Wallace" julga ter incorporado por inteiro. Eis o que ele tem a dizer sobre o colega:

O que colegas logorreicos como Fogle falhavam em entender é que há tipos vastamente distintos de verdade, alguns dos quais incompatíveis entre si. Por exemplo: uma lista $100 \%$ acurada e exaustiva do tamanho e formato exato de cada folha do gramado na frente da minha casa é "verdadeira", mas não é uma verdade na qual alguém vai ter qualquer interesse. O que torna uma verdade significativa, faz com que valha a pena, etc., é a sua relevância, o que por sua vez requer discernimento e sensibilidade extraordinárias ao contexto, a questões de valor, ao sentido geral - caso contrário, poderíamos simplesmente ser computadores transmitindo dados brutos uns aos outros. ${ }^{25}$

Da perspectiva de uma "lição de vida", o alcance da sabedoria de Wallace parece, a essa altura, um tanto limitado. Por outro lado, a nossa hipótese é a de que, como problema de forma narrativa, ela diz respeito à mecânica básica de qualquer descrição realista, e escancara uma versão ainda mais extrema - e significativa para a ficção contemporânea, eu gostaria de sugerir - de uma intuição de Roland Barthes, dita en passant em seu célebre ensaio sobre o efeito de real, acerca do "caráter

\footnotetext{
${ }^{24}$ WALLACE. The Pale King, p. 70.

25 "What logorrheic colleagues like Fogle failed to understand is that there are vastly different kinds of truth, some of which are incompatible with one another. Example: a 100 percent accurate, comprehensive list of the exact size and shape of every blade of grass in my front lawn is 'true', but it is not a truth that anyone will have any interest in. What renders a truth meaningful, worthwhile, \&c. is its relevance, which in turn requires extraordinary discernment and sensitivity to context, questions of value, and overall point - otherwise we might as well all just be computers downloading raw data to one another" (WALLACE. The Pale King, p. 261, tradução minha).
} 
enigmático de qualquer descrição". ${ }^{26}$ Pois a lição de Wallace parece ser dada no melhor espírito de "Faça o que eu digo, mas não faça o que eu faço": em incontáveis momentos - como a caracterização minuciosa do trânsito na cidade de Peoria, que dura inacreditáveis 14 páginas -, as descrições de The Pale King (e do resto da ficção do escritor) parecem estar mais próximas da lista exaustiva das folhas de grama do que de qualquer significado geral: muita informação, pouco ou nenhum sentido.

Um pouco mais sobre "O efeito de real", então, para tentarmos esclarecer melhor a questão. Como se sabe, de acordo com Barthes, a descrição realista de um escritor como Flaubert se equilibra entre, de um lado, o respeito às convenções da beleza que remontam ao discurso epidíctico, e que estavam em franco processo de esfacelamento (posto que suas convenções no mínimo já se encontravam passíveis de serem estendidas a quaisquer objetos, como com Felicité e seu papagaio empalhado); e, de outro, as injunções de uma realidade que se apresenta como avessa ao sentido (um princípio contido na própria ideia de detalhe irrelevante), mas que legitima o relato ficcional ao provê-lo de rebarbas, cuja superfluidade conota a ideia de que aquilo que é relatado aconteceu, ou ao menos se estrutura como algo que poderia ter acontecido, com direito a detalhes sem importância como os da vida. A injunção referencial serve de freio a uma linguagem convencionada, que poderia sem ela soar excessivamente artificial ou formulaica, enquanto o ideal de beleza faria frente por sua vez àquilo que Barthes denomina de "vertigem da notação". ${ }^{27}$ Ora, esquematicamente, poderíamos dizer que na ficção de Wallace - e talvez não só nela - a beleza convencionada simplesmente não existe mais enquanto tal, restando apenas sua contraparte, uma vertigem da notação incapaz de qualquer determinação imanente que sirva para esgotar cada impulso descritivo, que fica assim como que entregue à listagem 100\% exaustiva de cada folha do gramado de David Wallace. E, se a situação de fato corresponde a isso, não é difícil supor que um problema tão fundamental na respiração narrativa reverbere nas demais camadas da produção ficcional wallaceana - com a possibilidade de extrapolação para a ficção contemporânea em geral.

Tal questão, que aparece como problema narrativo na ficção do escritor, pode dizer respeito em última instância à difícil relação entre

${ }^{26}$ BARTHES. O rumor da língua, p. 183.

${ }^{27}$ BARTHES. O rumor da língua, p. 186. 
informação e sentido em uma situação histórica na qual se produz e manipula quantidades de dados monstruosamente grandes, e que tendem a ser cada vez maiores - algo que é discutido pelo próprio Wallace, especialmente no ensaio "Deciderization 2007". ${ }^{28}$ Pois o discurso indireto livre, ao se aproximar de Claude Sylvanshine, outro dos agentes do IRS, não deixa de sugerir a vertigem da notação barthesiana, mas convertida em forma de subjetivação. A roupagem é um pouco jocosa, com considerações pseudocientíficas a respeito da condição paranormal menor de que Sylvanshine sofre; mas bem poderia ser profética, se levarmos a sério as reflexões de um pensador como Christoph Türcke acerca das transformações na faculdade humana da atenção, que talvez esteja rumando em direção ao desaparecimento - ao menos na forma como a entendemos hoje. ${ }^{29}$ Pois a deficiência telepática de Sylvanshine, que tem algo da força descritiva de Wallace, consiste em

lampejos súbitos de ideias ou percepções [...] estruturalmente similares, mas em geral muito mais entediantes e cotidianas do que as previsões dramaticamente relevantes que normalmente concebemos como PES ou precognição. [...] Nos poucos estudos e monografias confiáveis existentes, os exemplos não obstante abundam; com efeito, a abundância, em conjunto com a irrelevância e a interrupção do pensamento e da atenção normais, compõem a essência do fenômeno da IFA [Intuição de Fatos Aleatórios]. O nome do meio de um amigo de infância de um estranho com quem cruzam em um corredor. [...] Vem de lugar algum, são inconvenientes e desconcertantes, como todas as irrupções psíquicas. É só que são efêmeras, inúteis, banais, dispersivas. ${ }^{30}$

\footnotetext{
${ }^{28} \mathrm{Cf}$. WALLACE. Both Flesh and Not: Essays.

${ }^{29} \mathrm{Cf}$. TÜRCKE. Hiperativos!.

30 "sudden flashes of insight or awareness [...] structurally similar to but usually far more tedious and quotidian than the dramatically relevant foreknowledge we normally conceive as ESP or precognition. [...] In what few reputable studies and monographs exist, examples nevertheless abound; indeed, abundance, together with irrelevance and the interruption of normal thought and attention, composes the essence of the RFI phenomenon. The middle name of the childhood friend of a stranger they pass in a hallway. [...] They come out of nowhere, are inconvenient and discomfiting like all psychic irruptions. It's just that they're ephemeral, useless, undramatic, distracting" (WALLACE, The Pale King, p. 120, tradução minha).
} 
Isso, por sua vez, nos leva de volta a algo que pode não ter ainda soado convincente: foi dito que o "terror de Bouvard e Pécuchet" de que falara Moretti torna a aparecer com uma roupagem nova na monotonia programática de The Pale King. Ao contrário do que postulou James Wood, o argumento aqui foi o de que não se tratava de questão de escolha, mas de uma solução formal para se lidar com uma situação histórica específica. Com o perdão pela obviedade gritante, os EUA da década de 1990 em diante e a França da segunda metade do século XIX configuram situações históricas... muito distintas, para dizer o mínimo. O que Flaubert e Wallace poderiam ter visto (ou ao menos expressado) de semelhante, então? Ou Wood tem razão, e a tal narrativa de imersão não passa de uma chatice "frustrante e enfim intolerável", mero desperdício dos talentos do escritor?

Como última hipótese, e à guisa de conclusão, podemos arriscar uma intuição combinada a partir de duas considerações pontuais - uma de Roberto Schwarz, a outra de Franco Moretti. Este último situa a Teoria do romance de Lukács em um "pequeno círculo de obras primas - os tableaux de Baudelaire, os romances de Flaubert, as pinturas de Manet, as peças de Ibsen, ou, com efeito, as últimas palestras de Weber - onde as regras da existência burguesa são tanto inelutáveis quanto falidas". ${ }^{31}$

E o mundo da ficção de Wallace não parece assim tão diferente desse. Ao contrário, é precisamente esse o núcleo da epifania de Fogle: o de que a vida como um todo é já "essencialmente penetrado e formado, as informações constitutivas do mundo já geradas, e que agora uma escolha significativa residia em arrebanhar, cercar e organizar esse fluxo torrencial de informação". ${ }^{32}$ Os adjetivos de Moretti precisam ser, contudo, matizados: de um lado, uma econômica definição de Schwarz, tomada quase ao acaso, indica que as tais regras surgem agora ainda mais inelutáveis do que antes - já que a "situação pós-moderna" pode ser grosso modo entendida "como aquela em que o capitalismo não é mais

\footnotetext{
31 "small circle of masterpieces - Baudelaire's tableaux, Flaubert's novels, Manet's paintings, Ibsen's plays, or, indeed, Weber's last lectures - where the rules of bourgeois existence are at once ineluctable and bankrupt" (MORETTI. Lukács's Theory of The Novel: Centenary Reflections", p. 41, tradução minha).

32 "essentially penetrated and formed, the real world's constituent info generated, and that now a meaningful choice lay in herding, corralling, and organizing that torrential flow of info" (WALLACE. The Pale King, p. 242, tradução minha).
} 
relativizado por um possível horizonte de superação"; 33 e, aproveitando o impulso característico do crítico, poderia inclusive ser acrescentado que essa inelutabilidade assume valências diversas no centro do capitalismo -i.e. a terra de Wallace, onde se manifesta principalmente como angústia existencial pouco ligada a dificuldades materiais - e em sua periferia -, onde a situação pode ser bem diferente. De outro lado, talvez nem tão falidas assim - ou, ao menos, leis com as quais poderíamos, para o escritor, aprender a conviver: pois a lição roubada pelo ficcionista, ao ser devolvida, parece perder algo de seu gume; Wallace quer ensinar seus leitores a prestarem mais atenção no mundo - uma forma melhorada de atenção, o que não deixa de soar como uma espécie de reformismo da percepção. Um certo pós-modernismo literário (tardio?) como variação ou hipérbole do estilo sério, mas sem degenerar em mero pastiche, e revisitando os problemas por ele deixados em aberto - pode ser um bom ponto de partida.

\section{Referências}

ADORNO, Theodor W. Introdução à sociologia. Tradução de Wolfgang Leo Maar. São Paulo: Unesp, 2007.

BARTHES, Roland. O rumor da língua. Tradução de Mario Laranjeira. São Paulo: Martins Fontes, 2012.

BENJAMIN, Walter. O narrador: considerações sobre a obra de Nikolai Leskov. In:__. Obras escolhidas: magia e técnica, arte e política. Tradução de Sergio Paulo Rouanet. São Paulo: Brasiliense, 1985. v. 1, p. 197-221.

FLAUBERT, Gustave. Bouvard e Pécuchet. Tradução de Marina Appenzeller e introdução de Stéphanie Dord-Crouslé. São Paulo: Estação Liberdade, 2007.

FLAUBERT, Gustave. Três contos. Tradução de Milton Hatoum e Samuel Titan Jr. São Paulo: Cosac Naify, 2004.

KIRN, Walter. A Not So Common Reader [Resenha de How Fiction Works, de J. Wood]. The New York Times. New York, 15 ago. 2008. Disponível em: <http://www.nytimes.com/2008/08/17/books/review/ Kirn-t.html>. Acesso em: 24 mar. 2018.

${ }^{33}$ SCHWARZ. Martinha versus Lucrécia, p. 79. 
LUKÁCS, Georg. Teoria do romance. Tradução de José Marcos Mariani de Macedo. São Paulo: Editora 34; Livraria duas cidades, 2003.

MORETTI, Franco. Lukács's Theory of The Novel: Centenary Reflections. New Left Review 91, p. 39-42, jan.-fev. 2014.

MORETTI, Franco. O burguês: entre história e literatura. Tradução de Alexandre Morales. São Paulo: Três estrelas, 2014.

MORETTI, Franco. O século sério. Tradução de Alipio Correa e Sandra Correa. Novos Estudos Cebrap, n. 65, p. 3-33, mar. 2003.

RANCIÈRE, Jacques. "Deleuze, Bartleby and The Literary Formula". In:__ The Flesh of Words: The Politics of Writing. Tradução de Charlotte Mandell. Stanford, California: Stanford University Press, 2004. p. 145-164.

RANCIÈRE, Jacques. O efeito de real e a política de ficção. Tradução de Carolina Santos. Novos Estudos Cebrap, n. 86, p.75-90, mar. 2010.

RANCIÈRE, Jacques. $O$ fio perdido: ensaios sobre a ficção moderna. Tradução de Marcelo Mori. São Paulo: Martins Fontes, 2017.

SCHWARZ, Roberto. Martinha versus Lucrécia: ensaios e entrevistas. São Paulo: Companhia das Letras, 2012.

SMITH, Zadie. Brief Interviews with Hideous Men: The Difficult Gifts of David Foster Wallace. In: . Changing My Mind: Occasional Essays. London; New York: Penguin Books, 2010. p.255-297.

TÜRCKE, Christoph. Hiperativos! Abaixo a cultura do déficit de atenção. Tradução de José Pedro Antunes. Rio de Janeiro; São Paulo: Paz e Terra, 2016.

WALLACE, David Foster. Both Flesh and Not: Essays. London: Penguin Books, 2012. 327p.

WALLACE, David Foster. Oblivion: Stories. New York; Boston: Little, Brown and Company; Back Bay Books, 2004.

WALLACE, David Foster. The Pale King. New York; Boston; London: Little, Brown and Company; Back Bay Books, 2011.

WOOD, James. Como funciona a ficção. Tradução de Denise Bottmann. São Paulo: Cosac Naify, 2011. 
WOOD, James. Remembering David Foster Wallace. Reluctant Habits, 15 sep. 2008. Disponível em: <http:/www.edrants.com/rememberingdavid-foster-wallace/>. Acesso em: 24 mar. 2018.

WOOD, James. The Digressionist [Resenha de Oblivion: Stories, de D.

F. Wallace]. The New Republic. New York, 9 ago. 2004, p. 26-31.

Recebido em: 20 de dezembro de 2017.

Aprovado em: 13 de março de 2018. 